\title{
CONFUSIONES CONTEMPORÁNEAS SOBRE GEOGRAFÍA ANTIGUA. A PROPÓSITO DEL SINUS TARTESII Y DEL LACUS LIGUSTINUS. ADDENDA ET CORRIGENDA
}

\author{
MODERN MISUNDERSTANDINGS ABOUT ANCIENT GEOGRAPHY. \\ IN RELATION TO SINUS TARTESII AND LACUS LIGUSTINUS \\ ADDENDA ET CORRIGENDA
}

\author{
EDUARDO FERRER ALBELDA*
}

\begin{abstract}
Resumen: El objetivo de estas líneas es corregir un error propio inserto en un artículo publicado en el anterior número de esta revista, en el que negaba la existencia de un sinus Atlanticus en la literatura latina. Sinus Atlanticus sí es un topónimo de la Ora Maritima de Avieno, aunque las conclusiones a las que llegamos no cambian: Avieno no refleja una geografía real, ni prerromana ni de su tiempo, y lacus Lugustinus es un hidrónimo exportado de la toponimia griega del sureste de Francia.

Palabras claves: Geografía, Iberia, Hispania, onomástica, Tarteso, lacus Ligustinus
\end{abstract}

En el anterior número de la revista Spal publiqué un estudio con el objetivo de hacer comprensible la onomástica relacionada con el entorno geográfico que hoy ocupan las marismas del Guadalquivir. Concretamente denunciamos la confusión que reina a la hora de identificar realidades geográficas contemporáneas con el topónimo sinus Tartesii y el hidrónimo lacus Ligustinus, ambos procedentes del poema Ora Maritima de Avieno (Ferrer 2012: 57-67).

\footnotetext{
* Departamento de Prehistoria y Arqueología, Facultad de Geografía e Historia, Universidad de Sevilla. C/ Doña María de Padilla s/n. 41004-Sevilla. Correo-e: eferrer@us.es
}

\begin{abstract}
The aim of these lines is to correct an own mistake inserted in an article published in Spal 21 (2012), where I denyed the existence of sinus Atlanticus in Latin literature. In effect sinus Atlanticus is a toponym of Avienus' Ora Maritima, but our conclusions don't change: Avienus didn't reflect a pre-roman geography and neither of his time. In the case of lacus Lugustinus, it's a hydronym exported of the Greek onomastic coming from the South-East of France.
\end{abstract}

Key words: Geography, Iberia, Hispania, onomastics, Tarteso, lacus Ligustinus

En la crítica a las identificaciones llevadas a cabo por O. Arteaga y A.M. Roos (2007: 63) entre estos sitios y los estudios geoarqueológicos, deslicé un error que debo enmendar. Refiriéndome a la correlación entre sinus Atlanticus, sinus Tartessius y Lacus Ligustinus con el golfo de Cádiz, con la antigua ensenada que hoy ocupan las marismas y con la plana de Sevilla, respectivamente, puse por escrito:

...el error de tal propuesta no reside en la delimitación de estas realidades marítimas sino en atribuir erróneamente nombres antiguos a estas. Para la primera, se ha propuesto el palabro sinus Atlanticus... De los tres, el primero no tiene refrendo en la 
literatura clásica, y Atlántico sería el nombre otorgado en la Antigüedad grecorromana al océano, no a una bahía o sinus (Ferrer 2012: 59).

Evidentemente sinus Atlanticus no es un palabro y sí tiene refrendo en la literatura latina, concretamente en el mismo Avieno:

El orbe de la anchurosa tierra yace extensamente / y alrededor del orbe fluye una y otra vez la ola. / Pero alli donde el profundo mar se introduce / desde el Océano, de manera que aqui el abismo del mar nuestro / se abre ampliamente, se encuentra el golfo Atlántico

(Ora Maritima 80-84,

trad. F.J. González Ponce 1995: 139)

Esta corrección no modifica, empero, las conclusiones a las que llegamos en dicho estudio, pues el argumento principal era que la onomástica utilizada por Avieno no se correspondía con una geografía real de las costas de Hispania sino con la acumulación con fines anticuaristas de topónimos e hidrónimos de origen diverso, algunos de los cuales constituían hápax. Concretamente Lacus Ligustinus no era un hidrónimo hispánico, sino originario del sureste de Francia, de la costa ligur, cercana al área de colonización focea, de donde proceden otros topónimos gemelos de Iberia. Un argumento que debe convencernos de la verosimilitud de lo que proponemos es que ningún geógrafo antiguo, ni anterior ni posterior a la conquista romana, hizo referencia a este lacus. Ni las fuentes de Estrabón, ni Plinio, ni Mela ni Ptolomeo hicieron mención de este hidrónimo, ni le otorgaron un nombre específico, aunque sí mencionaron las ciudades que se asentaban en sus contornos, como Asta, Eboura, Nabrissa o Conobaria, a las que se accedían durante la pleamar por los esteros (Estrabón III 1.9).

En realidad no se trataba de un lacus, y en tiempos de Avieno tampoco era un sinus, sino un antiguo estuario que se había convertido en una zona pantanosa atravesada por un río serpenteante. No obstante, el hidrónimo es aceptado comúnmente en la historiografía, y como no disponemos de nombre antiguo para esa realidad geográfica, creemos que es más productivo continuar usándolo, siempre y cuando no sea confundido con el sinus Tartessii, que sí puede ser identificado con el golfo de Cádiz. En este caso sí podemos encontrar topónimos antiguos, anteriores a la conquista romana, que pueden servir de argumento probatorio. Nuevamente Estrabón (III 2.11) comenta que "como las desembocaduras del río [Betis] son dos, se dice que en el territorio intermedio se había edificado anteriormente una ciudad, a la que llamaban Tarteso, con el mismo nombre que el río, y Tartéside a la tierra, que los túrdulos habitan en la actualidad. También Eratóstenes afirma que se llamaba Tarteside a la región que linda con Calpe,..." (trad. J. Gómez Espelosín 2007: 191). Es decir, el territorio que se extendía más allá de las Columnas de Heracles era denominado Tartéside, la tierra de los tartesios, y por ello este extenso litoral en forma de arco pudo ser conocido como sinus Tartesii.

\section{BIBLIOGRAFÍA}

Arteaga, O. y Roos A.M. (2007): "Carmona en el paisaje antiguo del Bajo Guadalquivir", M. Bendala Galán y M. Belén Deamos (dirs.), El nacimiento de la ciudad: la Carmona protohistórica. Actas del $V$ Congreso de Historia de Carmona, pp. 43-111. Carmona, Universidad de Sevilla-Ayuntamiento de Carmona.

Estrabón (2007): Estrabón. Geografía de Iberia. Traducción de J. Gómez Espelosín; presentaciones, notas y comentarios de G. Cruz Andreotti, M.V. García Quintela y J. Gómez Espelosín. Madrid, Alianza Editorial.

Ferrer Albelda, E. (2012): “Confusiones contemporáneas sobre geografía antigua. A propósito del Sinus Tartesii y del Lacus Ligustinus". Spal 21: 57-67. http://dx.doi.org/10.12795/spal.2012.i21.03

González Ponce, F.J. (1995): Avieno y el periplo. Écija, Gráficas Sol. 